\title{
Chronic Transient Hypoxia Alleviates High Fat Diet- Induced Obesity and Fatty Liver in C57 Mice by Upregulating Epinephrine Levels and Activation of AMPK
}

\author{
Yunfei Luo \\ Nanchang University https://orcid.org/0000-0002-6838-5950 \\ Zhijun Luo ( $D$ 857375930@qq.com ) \\ Nanchang University
}

\section{Research Article}

Keywords: Chronic transient hypoxia, obesity, fatty liver, epinephrine, inflammation.

Posted Date: March 12th, 2021

DOI: https://doi.org/10.21203/rs.3.rs-283059/v1

License: (a) (1) This work is licensed under a Creative Commons Attribution 4.0 International License. Read Full License 


\section{Abstract \\ Background}

According to epidemiologic studies, it was found that people living in high altitude areas have a lower prevalence of obesity and diabetes, and the main environmental differences between high altitude areas and plain areas are temperature and oxygen concentration. In this study, we investigated the effect of chronic transient hypoxia on obesity and fatty liver caused by high-fat diet in mice.

\section{Methods}

Put the mice under $10 \%$ oxygen concentration for 1 hour every day, this method is different from high altitude hypoxia and will not cause a series of acute altitude sicknesses. Intraperitoneal injection of epinephrine or propranolol was employed to examine the effect of chronic transient hypoxia on HFDinduced obesity, hyperglycemia and hepatic lipid accumulation.

\section{Results}

It showed that chronic transient hypoxia environment reduces the weight of mice and improve glucose tolerance, reduce the fat content of mice and alleviate fatty liver, reduces liver fat synthesis, promotes the expression M2 phenotype of macrophage genes in liver and thermogenic genes in brown fat. Furthermore, we showed that blocking the rise of epinephrine will compromise the chronic transient hypoxia environment beneficial ability to obesity and fatty liver, diminished expression of the liver AMPK phosphorylation and CD206.

\section{Conclusions}

These results suggest that chronic transient hypoxia activation of AMPK, induction of M2 type macrophage marker CD206 expression in the liver leads to significant weight loss and remission the severity of fatty liver through the adrenergic system.

\section{Introduction}

Overweight and obesity are defined as the abnormal or excessive accumulation of fat, leading to the impairment of health. Between 1975 and 2016, the prevalence of obesity almost tripled, with at least 2.8 million people dying of overweight or obesity each year[1]. Along with obesity continues to develop, it will considerably augment the risk of type 2 diabetes (T2DM), non-alcoholic fatty liver (NAFLD), obstructive sleep apnea, myocardial infarction (CAD) and other diseases[2]. Due to the deficiency of approved medical treatment measures for NAFLD, reducing obesity will bring many benefits to people's health, and is an effective strategy for NAFLD treatment, it can reduce blood lipids and diminish the 
incidence of fatty liver[3]. Thus, it is extremely necessary to find an effective, low side effect and good patient compliance treatment.

Interestingly, according to epidemiologic studies, it was found that people living in high altitude areas have a lower prevalence of obesity and diabetes[4,5], and the main environmental differences between high altitude areas and plain areas are temperature and oxygen concentration, there are also have studies confirmed that cold stimulation would be an effective method to treat obesity[6]. Yet the study of oxygen concentration is still needed to be clarified, which are primarily due to the different methods of hypoxia (time, oxygen concentration, hypoxia mode, etc.) [7], and the conclusions drawn are not consistent.

The hypoxia method we treated with mice in this research is to put it under $10 \%$ oxygen concentration for 1 hour every day, this method is different from high altitude hypoxia and will not cause a series of acute altitude sicknesses. It is well established that exercise stimulates the production of epinephrine[8], and hypoxia environment as a stimulus also increases the level of epinephrine[9]. However, the current research methods on hypoxia due to the prolonged exposure to hypoxia, the oxygen concentration is too low, and the pattern of hypoxia is complicated [7], which become limiting factors for the significance of clinical application. We expect that our chronic transient hypoxia environment can achieve the effect of exercise, our research found that when mice are exposed to $10 \%$ oxygen for one hour every day, it can slow down the weight gain of high-fat-induced obese mice (DIO) and remission the severity of fatty liver, it also activation of AMPK, induction of M2 type macrophage marker CD206 expression in liver and elevated levels of serum epinephrine.

\section{Materials And Methods}

\section{Mice}

All the animal experiments were conducted after the approval by the Animal Care and Use Committee of Medical College of Nanchang University. C57BL/ 6 mice (male, 5 weeks old, SPF grade, from Model Animal Research Center Of Nanjing University) were used, weighing about $20 \mathrm{~g}$. The mice were housed in the IVC environment, with a temperature of $23 \pm 2{ }^{\circ} \mathrm{C}$, the humidity of $40-50 \%$, and a light-dark cycle of $12 \mathrm{~h}$. Eat and drink at free. The indoor noise is controlled under $60 \mathrm{db}$, and the standard of the animal room is the second-level biological safety animal room. The operating procedures are under the second-level biological safety conditions. Perform various animal operations on the ultra-clean workbench.

Throughout the experiment, the behavior of the mice (when moving, eating, or interacting with other mice) was normal. Use the high-fat diet(60 kcal\% fat; D12492, Research Diets Inc., USA) to establish the obesity models.

\section{Glucose Tolerance Test (GTT) and Insulin Tolerance Test (ITT)}


In the $12^{\text {th }}$ week, the mice were fasted for about 12 hours but freely for water. Intraperitoneal injection of $2 \mathrm{~g} / \mathrm{kg}$ glucose for Glucose Tolerance Test. One week later, the mice were fasted for about 4 hours and intraperitoneal injection of $0.75 \mathrm{U} / \mathrm{kg}$ insulin for Insulin Tolerance Test.

\section{Serum and Hepatic Parameter Analysis}

As the resting time increases, the epinephrine level of the mice will gradually return to normal after hypoxia. Therefore, we need to collect the mice's blood in time after the hypoxia is completed and stand on ice for 10 minutes and centrifuge at $3000 \mathrm{rpm}$ to isolate serum in 10 minutes. The epinephrine was measured using the ELISA kit, which is purchased from Abnova, catalog KA1882. The experimental operation is performed according to the instructions, samples are extracted and acetylated and then proceed to epinephrine ELISA. The serum concentrations of alanine aminotransferase (ALT), aspartate aminotransferase (AST), and the liver tissue concentrations of triacylglycerol (TG), total cholesterol (TC) were determined by commercially available kits.

\section{Western Blot}

Weigh about $10 \mathrm{mg}$ of liver tissue, cut it into small pieces with scissors, mix well with PBS or red blood cell lysate, centrifuge at low speed to discard the liquid, then use liquid nitrogen for quick freezing and grinding, after grinding, add the prepared protein lysate to extract tissue protein, Lysis for 30 minutes on a vertical suspension in a chromatography refrigerator at $4^{\circ} \mathrm{C}$. Centrifuge at $12000 \mathrm{rpm}$ at $4^{\circ} \mathrm{C}$ for 15 minutes, and transfer the supernatant to a new EP tube.

To determine the protein concentration by the BCA method, adjust the protein lysate to the same concentration, mix it with $6 x$ loading buffer (5:1) to prepare the sample solution, cook the protein at $100^{\circ} \mathrm{C}$ for 10 minutes, and then store it in the refrigerator at $-20^{\circ} \mathrm{C}$. Excess protein samples are stored in aliquots in a refrigerator at $-80^{\circ} \mathrm{C}$. Prepare $10 \%$ SDS-PAGE gel, the sample amount of protein is about $30 \mu \mathrm{g}, 80 \mathrm{~V}$ pre-electrophoresis for $30 \mathrm{~min}$, then $120 \mathrm{~V}$ run for about one and a half hours, according to the molecular weight, then transferred to PVDF membrane. Block with $5 \%$ milk powder blocking solution for 1-2 hours, remove the membrane and wash it with TBST for a while, put it in the primary antibody, and incubate overnight in a vertical suspension in a chromatography refrigerator at $4^{\circ} \mathrm{C}$. Wash with TBST for $10 \mathrm{~min} \times 3$ times, incubated with secondary antibody for 1-2 hours at room temperature, wash with TBST for $10 \mathrm{~min} \times 3$ times, and immunoreactive bands were performed by ECL. Use Image $\mathrm{J}$ software to analyze the exposed protein band densities. (gapdh,5174T, CST; UCP1, ab209483, Abcam; Fas, 610963, bdbiosciences; ACC,3662, CST; P-AMPK, ab23875, Abcam; PGC1a,ab54481, Abcam; PKAc,ab76238, Abcam; ADR 33 ,ab94506, Abcam; CPT1A, ab128568, Abcam; CD206,ab64693, Abcam)

\section{Histopathology, oil red 0 , and immunohistochemistry}


The mice liver and adipose tissue were harvested, photographed, weighed, and part of the liver or adipose tissue fixed with $4 \%$ paraformaldehyde. Embedded in paraffin, and stained with hematoxylin and eosin (H\&E staining). For immunohistochemical analysis, the primary antibody was UCP1 (dilution of 1:500, ab135372, abcam), PPARy (dilution of 1:200, ab59256, abcam), Fas (dilution of 1:500, bdbiosciences, 610963), CPT1A(dilution of 1:200, ab128568, abcam), CD206(dilution of 1:100, ab64693, abcam) and the secondary rabbit anti-rat secondary antibody from zsbio. The remaining part of the liver was used to frozen sections $(10 \mu \mathrm{m}$ thickness) for oil red 0.

\section{Quantitative reverse transcriptase polymerase chain reaction (RT-PCR)}

RNA was isolated from fresh-frozen liver sections and amplified for RTPCR in triplicate as described previously using primers from the PrimerBank (https://pga.mgh.harvard.edu/primerbank/). Gene expression was calculated as a percent of GAPDH and mean fold change relative to a normal oxygen environment and chow diet mouse tissue was determined.

\section{Statistical Analysis}

Quantitative data sets were analyzed using GraphPad Prism software. Data are presented as mean \pm SEM and analyzed using Student's t-test, one- or two-way ANOVA with Sidak post hoc test. Pख0.05 was considered significant.

\section{Results}

\section{Chronic transient hypoxia environment reduce the weight of mice and improve glucose tolerance}

The mouse experiment divided into five groups(Fig. 1a), the method of hypoxia is that the mice are put into the animal hypoxia incubator at a fixed time every day, and when the oxygen concentration reaches $10 \%$, the time is started for one hour, and the food fed to the mice is weighed and recorded each time. The trend of mouse body weight change is shown in Fig. 1b, among the mice induced by high fat, the average body weight of mice under normal oxygen condition gradually increased from $23.43 \mathrm{~g}$ in the first week to $48.90 \mathrm{~g}$ in the 12th week, which was significantly higher than that the mice under chronic transient hypoxia environment. And whether it starts chronic transient hypoxia at the same time as high-fat induction (the weight from the beginning of $24.40 \mathrm{~g}$ to $40.65 \mathrm{~g}$ ), or after high-fat induced mice four weeks starts chronic transient hypoxia (the weight from the beginning of $21.70 \mathrm{~g}$ to $38.40 \mathrm{~g}$ ), the body weight of mice was lighter than that of mice induced by high-fat diet under normal oxygen (two way anova, $\mathrm{p}<$ 0.001), while the chronic transient hypoxia environment showed no significant difference in body weight for mice with chow diet. And by comparing the mice weight gained(Fig. 1c), it was found that the body weight of mice induced by high-fat diet under normoxic conditions was significantly greater than that of two groups of mice induced by high-fat diet under chronic transient hypoxia environment, both showed $p$ 
$<0.05$. In the other two groups of mice with a chow diet, the mice body weight did not increase much during the experiment.

We conducted GTT on the mice(Fig. 1e), it was found that the high-fat-induced fasting blood glucose of mice under normoxic oxygen environment reached a concentration of $9.33 \mathrm{mmol} / \mathrm{L}$, which higher than the fasting blood glucose standard of diabetes $(7 \mathrm{mmol} / \mathrm{L})$, it proves that the mice have suffered from high-fat induced hyperglycemia. The fasting blood glucose concentration of obese mice who had been intermittently stimulated by the hypoxic environment was $6.77 \mathrm{mmol} / \mathrm{L}$. There was a significant difference in fasting blood glucose between the two groups of mice (t-test, $p<0.001$ ), but the chronic transient hypoxia start after four weeks of high-fat induction, the fasting blood glucose was not significantly improved(Fig. 1d). About one week after the mouse GTT experiment, the mice were tested for insulin resistance(Fig. 1f). After the mice were injected with insulin, the initial blood glucose value of obese mice under normal oxygen environment was $9.6 \mathrm{mmol} / \mathrm{L}$. After 30 minutes, the blood glucose reached $5.6 \mathrm{mmol} / \mathrm{L}$, which no longer dropped significantly, and the chronic transient hypoxia environment began four weeks after the induction of high fat, the initial blood glucose value was 9.02 $\mathrm{mmol} / \mathrm{L}$, and the blood glucose concentration was reduced to $4.21 \mathrm{mmol} / \mathrm{L}$. Two-way anova statistical analysis was performed between the two groups, and there was a significant statistical difference $(p<$ 0.05). Obese mice start chronic transient hypoxia at the same time fed high-fat induction has improved insulin resistance, but there is no statistical difference compared with obese mice under normoxic environment.

\section{Chronic transient hypoxia environment reduce the fat content of mice and promotes the expression of thermogenic genes in brown fat}

We weighed the adipose tissue and liver of mice and found that chronic transient hypoxia reduced subcutaneous and perirenal fat weights in obese mice (t-test, $p<0.001$ ), while statistical analysis of brown fat at the scapulae found that brown fat weights were significantly lower in obese mice stimulated by chronic transient hypoxia than in obese mice under normoxic conditions (t-test, $p<0.001$ ), due to chronic transient hypoxia leading to a reduction in high-fat-induced brown fat "whitening"(Fig. 2a,b,c,d). Besides, it was found that the liver weight of obese mice stimulated by chronic transient hypoxia environments was also significantly reduced compared to obese mice in normoxic environments (t-test, $p$ $<0.001)$. Whereas chronic transient hypoxia in mice on a chow diet for a long period did not significantly affect differences in these indicators. Meanwhile, H\&E staining of white and brown fat was observed to significantly reduce the size of fat particles in obese mice with chronic transient hypoxia environment(Fig. 2e).

Brown adipose tissue from mice, observed by IHC staining, showed that chronic transient hypoxia environment resulted in elevated expression of the marker proteins of brown adipose PPARy(t-test, $\mathrm{p}<$ $0.001)$ and UCP1(t-test, $p<0.05)$ proteins, which was significantly different from the group of obese mice under normoxic environment (Fig. 3f,g,h). 


\section{Chronic transient hypoxia environment alleviate fatty liver, reduces liver fat synthesis and promotes the expression of M2 phenotype macrophage genes in liver}

Western-blot testing of liver tissues revealed that the chronic transient hypoxia environment elevated the expression of UCP1 protein which representing fatty acid oxidation capacity in the liver and was significantly different from the group of obese mice under normoxic environment (t-test, $p<0.05)$. At the same time, fatty acid synthetase, which is closely related to fatty acid synthesis, was down-regulated compared to the high-fat induced mice under normoxic conditions, although there was no significant difference (Fig. 3a,b,c).

From collected mouse liver tissue (Fig. 2d), it was found that the livers of mice induced by high-fat under normoxic environment were white, and the white granularity of the liver surface was more clearly observed under the stereomicroscope, while the livers of obese mice stimulated by chronic transient hypoxia environment appeared reduced white in appearance. Subsequently, liver tissue was dehydrationembedded sectioned, and H\&E staining of the liver was observed under the microscope, the results showed that the liver tissue of the high-fat induced mice under normoxic environment was scattered with a large number of fat particles and even vacuoles, while the fat particles were significantly reduced in the obese mice stimulated by chronic transient hypoxia environment. Further, frozen liver sections were stained with oil red $\mathrm{O}$ to observe lipid droplet infiltration in liver tissues, and it was found that mice with high-fat induction under normoxic environment were very rich in lipid droplet content.

RT-PCR experiments were performed on some genes related to adipose metabolism in liver tissues to examine their expression levels, and the results showed that chronic transient hypoxia environment reduced the mRNA expression level of SCD1, a gene related to adipose synthesis in the liver, with a significant difference compared with the obese mouse group under normoxic environment (t-test, $p<$ 0.05). At the same time, the expression levels of genes closely related to the oxidative of fatty acids were significantly elevated, such as PGC1a, ATGL, PPARa, and UCP1 compared with the high-fat induced mice under normoxic conditions (t-test, $\mathrm{p}<0.05$ ), and CPT1A also raised, although there was no significant difference. In addition, the expression of adrenergic receptor ADR3 also increased significantly (t-test, $p<$ 0.05) (Fig. 3e).

Macrophage M2 type marker associated gene expression levels showed that high-fat induced obesity resulted in a decrease in arginase expression with a statistical difference (t-test, $p<0.05)$ compared to normal diet mice, whereas chronic transient hypoxia environmental stimulation resulted in elevated expression, and CD206 expression levels were also elevated under chronic transient hypoxia conditions, but there was no statistical difference compared to the group of high lipid-induced obese mice under normoxic conditions (Fig. 3f).

Blocking the rise of epinephrine will weaken the ability of chronic transient hypoxia environment to reduce the weight of mice and improve glucose tolerance 
The mice were divided into five groups and the amount of epinephrine administered intraperitoneally was $0.1 \mathrm{mg} / \mathrm{kg}$ and the amount of propranolol administered intraperitoneally was $2 \mathrm{mg} / \mathrm{kg}$ (Fig. $4 \mathrm{a})$.

After one week of acclimation in the animal room, mice were started to be given a high-fat diet for induction, their body weight was measured at fixed times per week, and after 4 weeks, the experiment was continued for 8 weeks with an intraperitoneal injection of epinephrine or chronic transient hypoxia environmental stimulation, and intraperitoneal injection of propranolol under hypoxic conditions. The trend of weight change in mice is shown in Fig. $4 \mathrm{~b}$. The body weight of high-fat induced mice under normoxic conditions was significantly higher than that of mice stimulated by chronic transient hypoxia environments or the mice injected intraperitoneally with epinephrine (two way anova, $p<0.001$ ), mice were given propranolol intraperitoneally under chronic transient hypoxia weighed more than mice with chronic transient hypoxia alone. We can find that the high fat diet under normoxic conditions is significantly obese than that of mice stimulated by chronic transient hypoxia environment or intraperitoneal injection of epinephrine, the amount of weight gain by t-test statistics all showed $p<$ 0.05(Fig. 4c), while the body size of mice stimulated by chronic transient hypoxia environment and intraperitoneal injection of propranolol is larger than that of mice stimulated by chronic transient hypoxia environment alone.

GTT of mice found that the high-fat induced fasting blood glucose of mice under normoxic conditions reached a concentration of $7.75 \mathrm{mmol} / \mathrm{L}$ (Fig. 4d,e), which was higher than the fasting blood glucose standard of diabetes of $7 \mathrm{mmol} / \mathrm{L}$, proving that the mice had suffered from high-fat induced high blood glucose, and the fasting blood glucose concentration of obese mice who intraperitoneal injection of epinephrine is $6.2 \mathrm{mmol} / \mathrm{L}$, there is a significant difference in blood glucose between the two groups of mice (t-test, $p<0.05$ ). The fasting blood glucose of obese mice under chronic transient hypoxia environment was also improved, with a concentration of $4.33 \mathrm{mmol} / \mathrm{L}$, but the fasting blood glucose of obese mice injected with propranolol was impaired, with a concentration of $8.01 \mathrm{mmol} / \mathrm{L}$, there is also a significant difference in blood glucose between the two groups of mice (t-test, $p<0.005)$. Two-way anova analysis of GTT blood glucose change curves of five groups in mice was found to have significant statistical differences, $p<0.001$. In the insulin resistance experiment of mice(Fig. 4f), it was found that the initial blood glucose value of obese mice under normoxic environment was $9.57 \mathrm{mmol} / \mathrm{L}$, and the blood glucose reached $3.91 \mathrm{mmol} / \mathrm{L}$ in about 30 minutes, which no longer dropped significantly. The initial blood glucose value of the mice under chronic transient hypoxia environment was $8.62 \mathrm{mmol} / \mathrm{L}$, and the blood glucose concentration was reduced to $2.34 \mathrm{mmol} / \mathrm{L}$, there was a significant statistical difference between the two groups (Two-way anova, $p<0.05$ ). Obese mice injected intraperitoneally with epinephrine initial blood glucose value is $8.44 \mathrm{mmol} / \mathrm{L}$, and the blood glucose concentration is reduced to $3.24 \mathrm{mmol} / \mathrm{L}$, which improves its insulin resistance. While the intraperitoneal injection of propranolol counteracts the beneficial effect of chronic transient hypoxia on insulin resistance.

To study the chronic transient hypoxia environment and the effect of intraperitoneal injection of epinephrine on serum epinephrine levels in mice(Fig. 4g), we collected blood from mice and centrifuged the serum for Elisa test of epinephrine, and found that chronic transient hypoxia environment will 
increase serum epinephrine levels, there is a statistically significant difference compared with obese mice under normoxic conditions (t-test, $\mathrm{p}<0.05$ ), and intraperitoneal injection of propranolol will reduce the effect of chronic transient hypoxia, intraperitoneal injection of epinephrine can also increase serum epinephrine levels, and compared with obese mice under normal oxygen environment, there is a significant difference (t-test, $p<0.05$ ). We also recorded the changes in the concentration of epinephrine in the serum of mice after one hour of hypoxia, it shows that the effect of hypoxia for 1 hour can last for almost a day. 0 point represents the timing point when hypoxia starts(Fig. 4h).

\section{Blocking the rise of epinephrine will weaken the ability of chronic transient hypoxia environment to reduce the fat content of mice and alleviate fatty liver}

H\&E staining of white fat and brown fat revealed that chronic transient hypoxia environment and intraperitoneal injection of epinephrine significantly reduced the size of fat particles in obese mice(Fig. 5a). However, intraperitoneal injection of propranolol in obese mice will weaken the effect of hypoxia on reducing these fats.

The liver surface of mice induced by high fat under normal oxygen environment is white, while the liver of obese mice stimulated by chronic transient hypoxia environment or intraperitoneal injection of epinephrine is less white in appearance(Fig. 5b). The H\&E staining results of the liver showed that the liver tissues of mice induced by high fat under normal oxygen environment were scattered with a large number of fat particles or even vacuoles, and the fat particles of obese mice with chronic transient hypoxia environment or intraperitoneal injection of epinephrine were significantly reduced. After intraperitoneal injection of propranolol in obese mice, it will weaken the hypoxic environment effect and aggravate fatty liver. The frozen sections of the liver were further stained with oil red 0 to observe the infiltration of lipid droplets in the liver tissue. The results showed that the lipid droplet content of the liver tissue in mice induced by high fat under normoxic conditions was very abundantly, chronic transient hypoxia environment, or intraperitoneal injection of epinephrine reduces lipid droplets in obese mice.

Continue to measure the content of triglycerides and cholesterol in the mouse liver(Fig. 5c,d). It was found that chronic transient hypoxia and intraperitoneal injection of epinephrine can reduce the triglyceride content in the liver of obese mice, and intraperitoneal injection of propranolol can offset this beneficial effect, it is significantly different when compared to the mice under chronic transient hypoxia environment ( $t$-test, $p<0.05$ ). Besides, chronic transient hypoxia environment and intraperitoneal injection of epinephrine also reduce the cholesterol content in the liver, which is significantly different from obese mice under normal oxygen environment ( $t$-test, $p<0.05)$. Propranolol reduces the effect of chronic transient hypoxia on liver cholesterol (t-test, $p<0.05)$.

\section{Blocking epinephrine elevation reduces the ability of chronic transient hypoxia environment increment in liver fat oxidation}

We collected the liver tissues of mice for Western-blot detection and found that chronic transient hypoxia environment and intraperitoneal injection of epinephrine increased the expression of UCP1 protein in the 
liver (Fig. 6a,b), which was significantly different from the obese mice group under normal oxygen environment (t-test, $p<0.05)$, contrariwise, intraperitoneal injection of propranolol have reduced the protein expression of UCP1. At the same time, Fas protein was strongly suppressed in the chronic transient hypoxia environment when compared to the obese mice group under normal oxygen environment (t-test, $p<0.01$ ), yet intraperitoneal injection of propranolol increased Fas protein expression (Fig. 6d). ACC, the rate-limiting enzyme for fat synthesis, was reduced in mice in the chronic transient hypoxia environment and intraperitoneal injection of epinephrine group and was significantly different from the high-fat induced mice under normoxic environment (t-test, $p<0.05$ ), but the intraperitoneal injection of propranolol group did not offset this part of the beneficial effect of chronic transient hypoxia environment (Fig. 6c). Chronic transient hypoxia environment and intraperitoneal injection of epinephrine boost the expression of ADR3(Adrenergic receptor $\beta 3$ ) and PKAc( cAMP-dependent protein kinase) as compared to the obese mice group under normal oxygen environment (t-test, $p<0.05$ or $p<0.01$ ), nevertheless, it displays a marked reduction in the intraperitoneal injection of propranolol group mice compared with only in chronic transient hypoxia environment group mice (t-test, $p<0.05$ or $p<0.01$, Fig. 6e,f). Furthermore, the expression levels of P-AMPK and PGC1a(Fig. $6 \mathrm{~g}, \mathrm{~h})$, which promote glucose transport and lipid oxidative decomposition, are increased in mice in the chronic transient hypoxia environment and intraperitoneal injection of epinephrine group, and there was a significant difference (ttest, $p<0.05$ ), while intraperitoneal injection of propranolol reduced its expression, and the level of PAMPK protein was significantly different from that of chronic transient hypoxia environment group (t-test, $p<0.05)$. Fatty acid synthetase in the intraperitoneal injection of epinephrine group was lower than that in high-fat diet induced mice under normal oxygen environment, but there was no significant difference.

IHC staining of liver tissue revealed that intraperitoneal injection of epinephrine and the chronic transient hypoxia group increased the expression of CPT1A protein(Fig. 6i,j), which plays a key role in fatty acid $\beta$ oxidation in the liver, and was significantly different from the obese mice group under normal oxygen environment ( $t$-test, $p<0.05$ ), while intraperitoneal injection of propranolol will reduce the expression of CPT1A protein when compared to the chronic transient hypoxia group (t-test, $p<0.05$ ). The expression of Fas(Fig. 6i,k), which is closely related to the synthesis of fatty acids, is significantly different between the chronic transient hypoxia group and the obese mice group under normal oxygen environment (t-test, $\mathrm{p}<$ 0.05), similarly, the epinephrine group also decreased, but there was no statistical difference compared with the normoxic obesity group, and intraperitoneal propranolol increased Fas protein expression, it was significantly different from the chronic transient hypoxia group (t-test, $p<0.01$ ).

RT-PCR experiments were performed on some genes related to fat metabolism in liver tissue(Fig. 6l), and their expression levels were detected. The results showed that the group of intraperitoneal injection of epinephrine compared with obese mice under normal oxygen, the mRNA expression level of ATGL, UCP2 increased, and there was a significant difference (t-test, $p<0.05$ ). At the same time, chronic transient hypoxia environment mice were intraperitoneally injected with propranolol, the mRNA expression level of C/EBP, CPT1A, adiponectin, and PPARa, and UCP1 were significantly lower than chronic transient hypoxia environment alone (t-test, $p<0.05$ ), expression levels of ADR3 (adrenergic receptor), PGC1a in the epinephrine group and chronic transient hypoxia group, there was also an increase, but have no statistical 
difference compared with the group of obese mice under normoxia, while intraperitoneal injection of propranolol reduced the expression of these genes.

\section{Blocking epinephrine elevation reduces the ability of chronic transient hypoxia environment to increase the expression of M2 macrophages in the liver}

To investigate whether chronic transient hypoxia environment or epinephrine affect the expression of M2type macrophage-related proteins in mouse liver tissue, Western-blot detection was performed, find that the protein expression level of M2 type macrophage marker CD206 both in the chronic transient hypoxia environment and intraperitoneal injection of epinephrine group mice were elevated(Fig. 7b,d), compared with the high-fat induced mice under normal oxygen environment, there was a significant difference (ttest, $p<0.05$ ), while the intraperitoneal injection of propranolol reduced its expression, which was significantly different from the chronic transient hypoxia environment group (t-test, $p<0.05$ ). The results of IHC also showed the same trend, but no statistics differences (Fig. 7a,c). Furthermore, the RT-PCR results show that intraperitoneal injection of epinephrine increasing the gene expressions of CD206(t-test, $p<0.05$ ) (Fig. 7e), while the intraperitoneal injection of propranolol diminished expression of M2 type macrophage marker Arginase-1, which was significantly different from the chronic transient hypoxia environment group (t-test, $p<0.05)$.

\section{Discussion}

Obesity is one of the major risk factors for NAFLD[10]. In experiments, C57BL/6 male mice fed with highfat diets showed histologically, both H\&E and Oil Red O staining to successfully induce fatty liver and increased systemic fat mass. It was also found that both glucose and insulin tolerance were affected in these C57BL/ 6 mice. The liver UCP1 protein and brown fat PPARy, UCP1 protein expression were also reduced. The chronic transient hypoxia environment mitigates these adverse effects of high fat, it can reducing body weight and fatty liver severity in obese mice, improving glucose tolerance, and increasing the expression of markers of M2 macrophages. After intraperitoneal injection of epinephrine in mice, the histopathological section of liver and oil red $\mathrm{O}$ staining, and the expression of liver-related metabolism genes or proteins, we found that it shows the same effect as chronic transient hypoxia environment, while intraperitoneal injection of propranolol in chronic transient hypoxia mice can significantly diminish these beneficial effects of chronic transient hypoxia. It can be speculated that the chronic transient hypoxia environment maybe by increasing epinephrine levels to achieve weight loss and improve fatty liver in obese mice.

Epinephrine is considered as an important metabolic hormone that favors mobilizing energy storage in the form of free fatty acids and glucose[11]. In response to exercise, it will lead to massive epinephrine levels increase in plasma[8]. Likewise, hypoxic environment as a stimulus factor can also increase the level of epinephrine[9], especially in well-trained subjects, it can be observed that hypoxia per se enhances the epinephrine response[12]. An increase in the concentration of serum epinephrine activates the adrenergic receptor $\beta 3$ in the liver[13]. $\beta 3-\mathrm{AR}$, act as an isoform of the adrenergic receptor, initiates the 
activation of protein kinase $A(P K A)$ [14]. It is well established that PKA is closely related to lipolysis[15], accomplished by activating the AMPK pathway, reducing lipid production, increasing fatty acid $\beta$ oxidation, and beneficial for improving liver lipid metabolism[16]. AMPK is a universal metabolic sensor that has a crucial role in maintaining lipid homeostasis[17], regulate fatty acid $\beta$-oxidation by activating PGC-1a[18], Moreover, the activation of AMPK can also boost the expression of CD206, which is highly expressed in M2 macrophages[19], and transform macrophages from a pro-inflammatory M1 phenotype to an anti-inflammatory M2 phenotype, subsequent reduction the deleterious inflammation[20].

These results indicate that chronic transient hypoxia environments can reduce body weight as well as fatty liver in obese mice. And according to the results of our experiment, chronic transient hypoxia may be developed into a non-invasive and effective choice for obesity and fatty liver combined with other clinical treatments.

The chronic transient hypoxia environment will affect the body's various systems. The mechanism involved is very complicated. We have only studied the increase of epinephrine and the reduction of fatty liver, especially the synthesis and oxidative decomposition of fat. Preliminary studies have been conducted on the changes of macrophages in the liver, and the specific in-depth mechanism has not been fully explored. In the future, the level of omics can be analyzed in mice to obtain a more comprehensive understanding of the effects of chronic transient hypoxia environment on the body. Metabolic cages can also be used to conduct detailed long-term follow-up studies on mice. Obesity will not only cause fatty liver but also cause other damages, such as inducing intestinal diseases[21]. It can also study chronic transient hypoxia environment to explore other complications that obesity will cause. Thorough research on the various effects of chronic transient hypoxia environment on the body will help to provide new research ideas for the treatment of obesity and fatty liver.

\section{Conclusions}

The principal of our study is found that exposure to chronic transient hypoxia environment $1 \mathrm{~h} /$ day, will not affect the appetite of mice, it can alleviation of the body weight gain in high-fat induced C57 obese mice, improve glucose tolerance. It can also ameliorate the severity of fatty liver in obese mice, reduces fat synthesis. Concurrently, it increases epinephrine levels and the expression of anti-inflammatory M2 macrophage markers. Intraperitoneal injection of epinephrine has a similar effect as a chronic transient hypoxia environment to improve the body weight and fatty liver of obese mice, and intraperitoneal injection of propranolol may counteract the part of beneficial effects in a hypoxic environment. Our results suggest that chronic transient hypoxia activation of AMPK, induction of M2 type macrophage marker CD206 expression in the liver leads to significant weight loss and remission the severity of fatty liver through the adrenergic system.

\section{Abbreviations}


high-fat diet; GTT:glucose tolerance test; ITT:insulin tolerance test; AST:aspartate aminotransferase; ALT:alanine aminotransferase.

\section{Declarations}

\section{Acknowledgments}

Not applicable.

\section{Authors' contributions}

All authors write冈read and approved the final manuscript.

\section{Funding}

This work was supported by National Nature Science Foundation of China $(81572753,31660332$, 81460374,31460304 and 81560299).

\section{Availability of data and materials}

The datasets used and/or analysed during the current study are available from the corresponding author on reasonable request.

\section{Ethics approval and consent to participate}

The animal protocol used was approved by the Animal Ethics Committee of the Nanchang University.

\section{Consent for publication}

Not applicable.

\section{Competing Interests}

The authors declare no potential conflicts of interest.

\section{References}

1. Hill JJ: Obesity: An Emerging Threat. J Natl Black Nurses Assoc 2018, 29:36-39.

2. Frühbeck G, Toplak H, Woodward E, Yumuk V, Maislos M, Oppert JM: Obesity: the gateway to ill health - an EASO position statement on a rising public health, clinical and scientific challenge in Europe. Obes Facts 2013, 6:117-120.

3. Ueno T, Sugawara H, Sujaku K, Hashimoto O, Tsuji R, Tamaki S, Torimura T, Inuzuka S, Sata M, Tanikawa K: Therapeutic effects of restricted diet and exercise in obese patients with fatty liver. $\mathrm{J}$ Hepatol 1997, 27:103-107. 
4. Woolcott $\mathrm{OO}$, Ader $\mathrm{M}$, Bergman RN: Glucose homeostasis during short-term and prolonged exposure to high altitudes. Endocr Rev 2015, 36:149-173.

5. Santos C, Bustamante A, Hedeker D, Vasconcelos O, Garganta R, Katzmarzyk PT, Maia J: Correlates of Overweight in Children and Adolescents Living at Different Altitudes: The Peruvian Health and Optimist Growth Study. J Obes 2019, 2019:2631713.

6. Xu Z, You W, Zhou Y, Chen W, Wang Y, Shan T: Cold-induced lipid dynamics and transcriptional programs in white adipose tissue. BMC Biol 2019, 17:74.

7. Yang YY, Li LY, Jiao XL, Jia LX, Zhang XP, Wang YL, Yang S, Li J, Du J, Wei YX, Qin YW: Intermittent Hypoxia Alleviates $\beta$-Aminopropionitrile Monofumarate Induced Thoracic Aortic Dissection in C57BL/ 6 Mice. Eur J Vasc Endovasc Surg 2019.

8. Mitsui T, Nakamura T, Fau - Ito T, Ito T, Fau - Umemoto Y, Umemoto Y. Fau - Sakamoto K, Sakamoto K Fau - Kinoshita T, Kinoshita T Fau - Nakagawa M, Nakagawa M Fau - Tajima F, Tajima F: Exercise significantly increases plasma adrenaline and oxidized low-density lipoprotein in normal healthy subjects but not in persons with spinal cord injury.

9. Blegen M, Cheatham C Fau - Caine-Bish N, Caine-Bish N Fau - Woolverton C, Woolverton C Fau Marcinkiewicz J, Marcinkiewicz J Fau - Glickman E, Glickman E: The immunological and metabolic responses to exercise of varying intensities in normoxic and hypoxic environments.

10. Tomic D, Kemp WW, Roberts SK: Nonalcoholic fatty liver disease: current concepts, epidemiology and management strategies. Eur J Gastroenterol Hepatol 2018, 30:1103-1115.

11. Verberne AJ, Korim WS, Sabetghadam A, Llewellyn-Smith IJ: Adrenaline: insights into its metabolic roles in hypoglycaemia and diabetes. Br J Pharmacol 2016, 173:1425-1437.

12. Kjaer M, Bangsbo J, Lortie G, Galbo H: Hormonal response to exercise in humans: influence of hypoxia and physical training. Am J Physiol 1988, 254:R197-203.

13. Lee SB, Kim HG, Lee JS, Kim WY, Lee MM, Kim YH, Lee JO, Kim HS, Son CG: Intermittent restraintinduced sympathetic activation attenuates hepatic steatosis and inflammation in a high-fat diet-fed mouse model. Am J Physiol Gastrointest Liver Physiol 2019, 317:G811-G823.

14. Wang LJ, Lin Y L: Small molecules for fat combustion: targeting obesity. Acta Pharm Sin B 2019, 9:220-236.

15. Larsson S, Jones HA, Göransson O, Degerman E, Holm C: Parathyroid hormone induces adipocyte lipolysis via PKA-mediated phosphorylation of hormone-sensitive lipase. Cell Signal 2016, 28:204213.

16. Xu HY, Yu L, Chen JH, Yang LN, Lin C, Shi XQ, Qin H: Sesamol Alleviates Obesity-Related Hepatic Steatosis via Activating Hepatic PKA Pathway. Nutrients 2020, 12.

17. Herzig S, Shaw RJ: AMPK: guardian of metabolism and mitochondrial homeostasis. Nat Rev Mol Cell Biol 2018, 19:121-135.

18. Li L, Xiao L, Hou Y, He Q, Zhu J, Li Y, Wu J, Zhao J, Yu S, Zhao Y: Sestrin2 Silencing Exacerbates Cerebral Ischemia/Reperfusion Injury by Decreasing Mitochondrial Biogenesis through the AMPK/PGC-1a Pathway in Rats. Sci Rep 2016, 6:30272. 
19. Fujisaka S, Usui I, Nawaz A, Takikawa A, Kado T, Igarashi Y, Tobe K: M2 macrophages in metabolism. Diabetol Int 2016, 7:342-351.

20. Wang, Huang Y, Xu Y, Ruan Y, Wang W, Zhang H, Saavedra Y, Zhang JM, Huang L Z, Pang T: A Dual AMPK/Nrf2 Activator Reduces Brain Inflammation After Stroke by Enhancing Microglia M2 Polarization. Antioxid Redox Signal 2018, 28:141-163.

21. Camilleri M, Malhi H, Acosta A: Gastrointestinal Complications of Obesity. Gastroenterology 2017, 152:1656-1670.

\section{Figures}
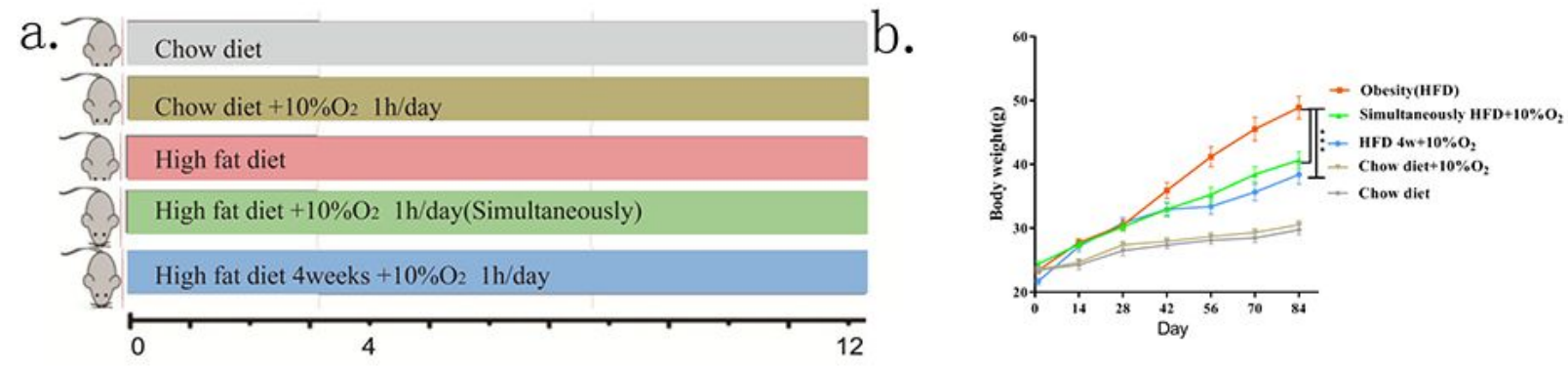

Fasting blood glucose

C.

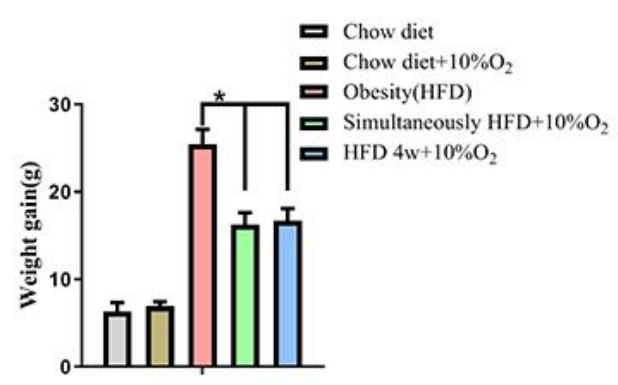

e.

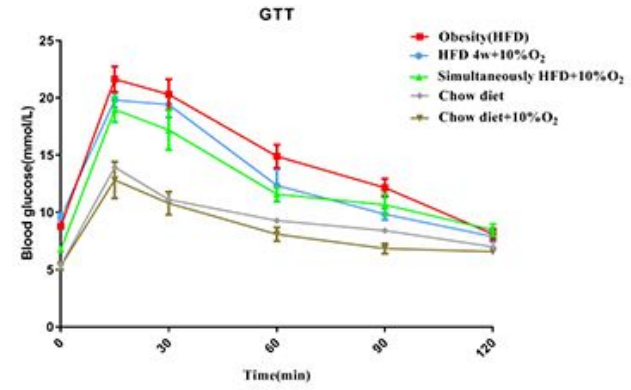

d.

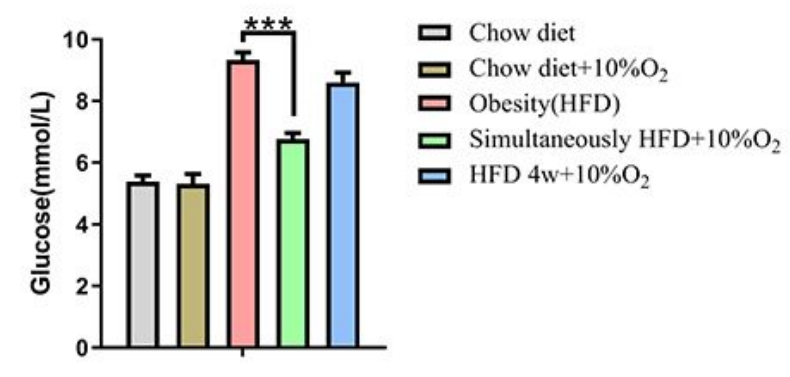

f.

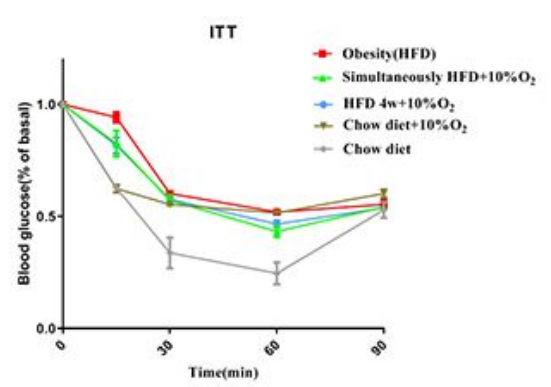

\section{Figure 1}

Chronic transient hypoxia environment reduce the weight of mice and improve glucose tolerance (a) The group of experimental mice $(n=8)$. $(b, c)$. Changes in the weight gain of mice during the experiment. $(d, e, f)$. 
Mice's GTT, ITT and fasting blood glucose.

a.

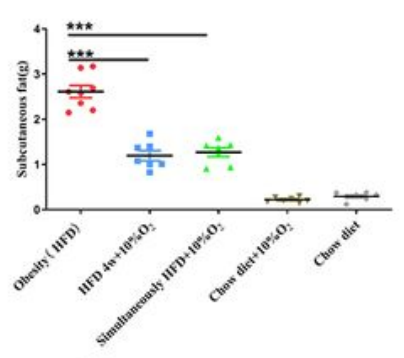

c.

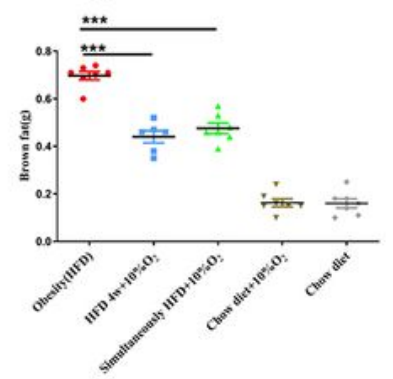

b.

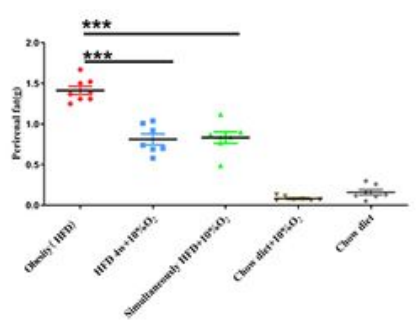

d.

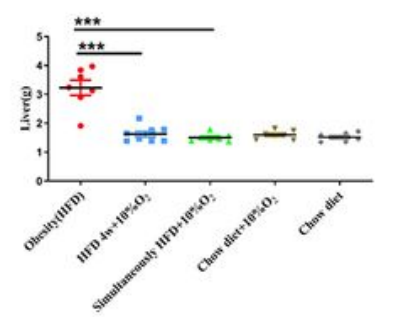

e.
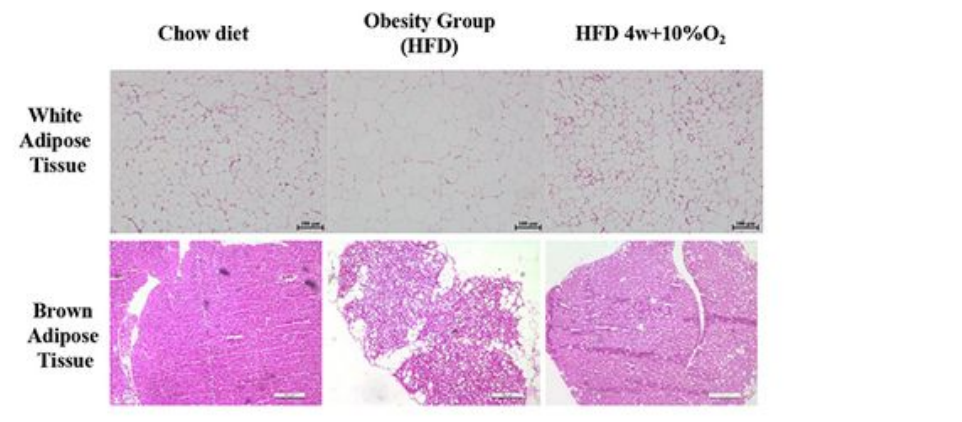

f.

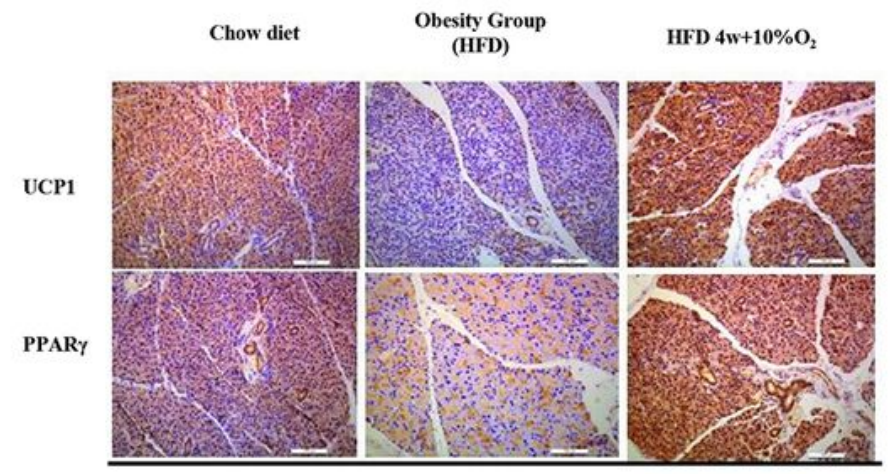

g.

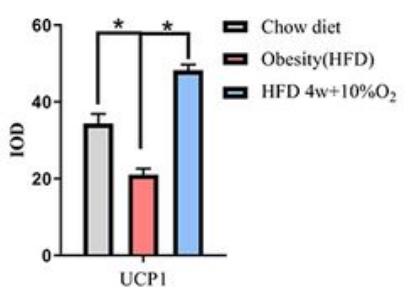

h.

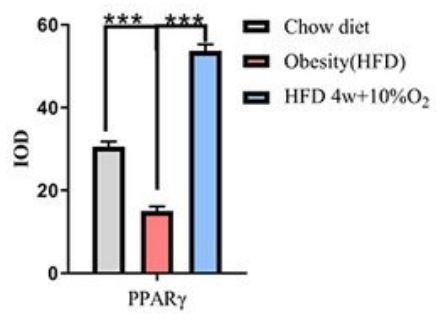

\section{Figure 2}

Chronic transient hypoxia environment reduce the fat content of mice and promotes the expression of thermogenic genes in brown fat $(a, b, c, d)$ The weight of mouse subcutaneous fat, perirenal fat, brown fat and liver. (e) H\&E staining results of mouse white fat and brown fat. (f,g,h). Expression of UCP1 and PPARY protein in mouse brown fat. 
a. UCP1 000

Fas

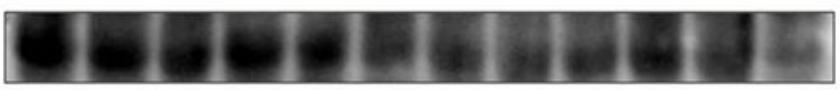

GAPDH

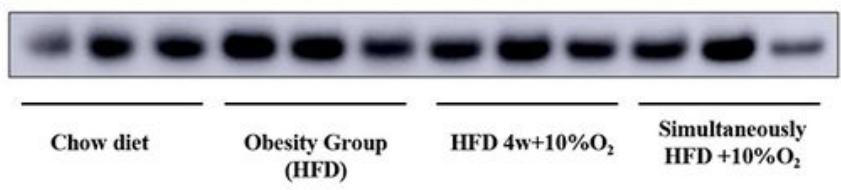

b.

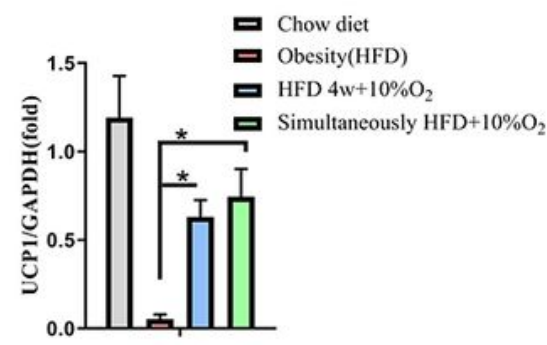

C.

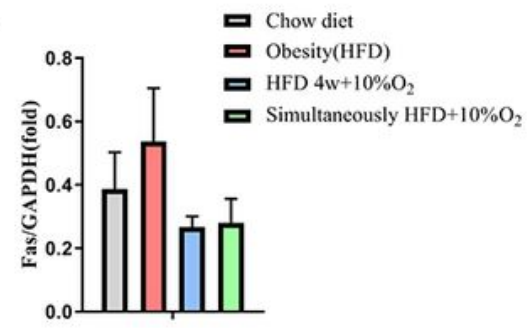

d.

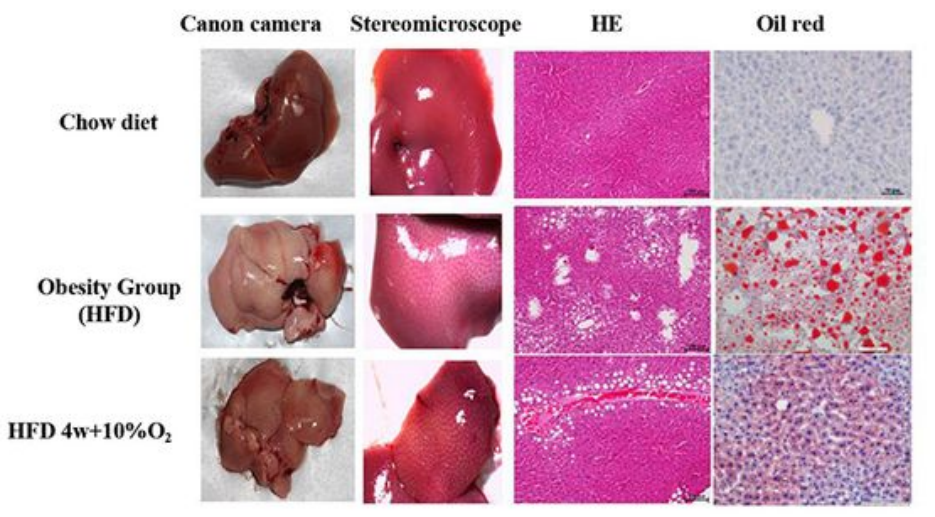

e.

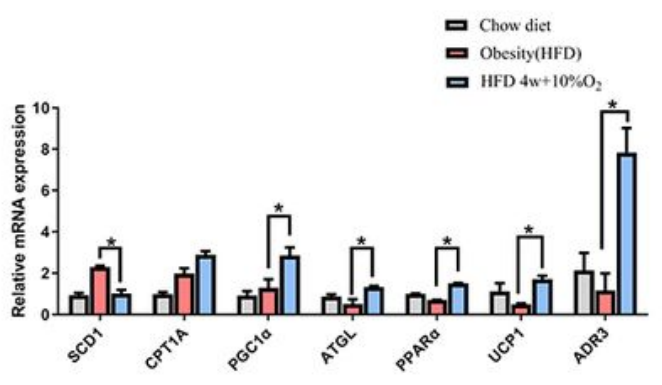

f.

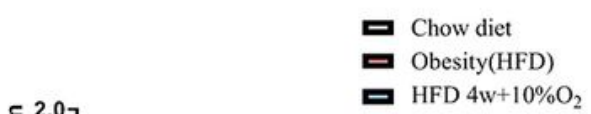

\section{Figure 3}

Chronic transient hypoxia environment alleviate fatty liver, reduces liver fat synthesis and promotes the expression of M2 phenotype macrophage genes in liver $(a, b, c)$ Expression of UCP1 and Fas proteins in the mouse liver. (d). The appearance of mouse liver and H\&E, oil red $O$ staining results. (e,f) Lipid synthesis and catabolism, M2-type macrophages marker related genes expression in mouse liver. 
a.

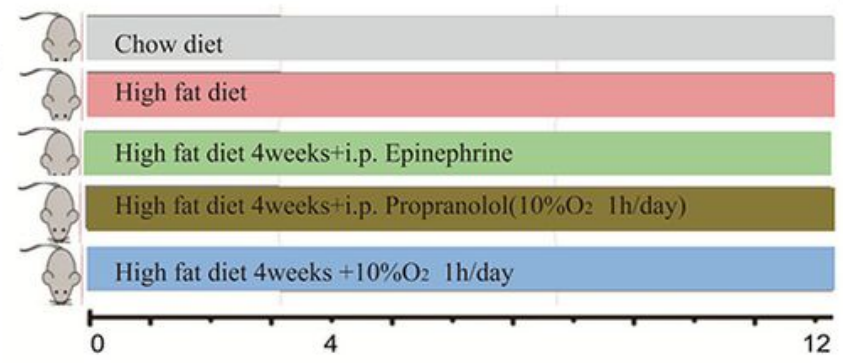

C.

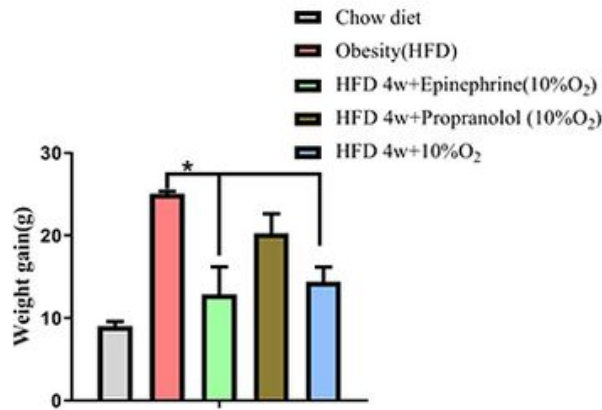

e.

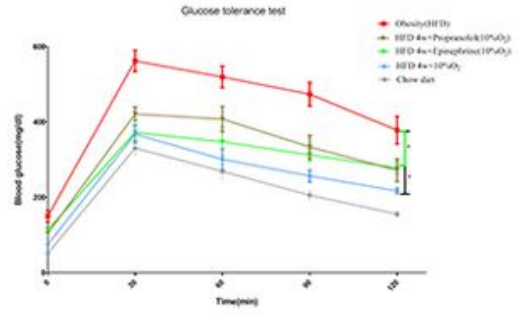

g.

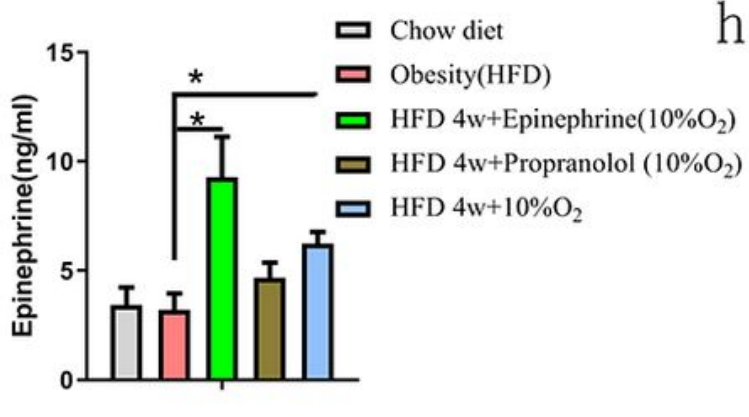

d.

f.

h.
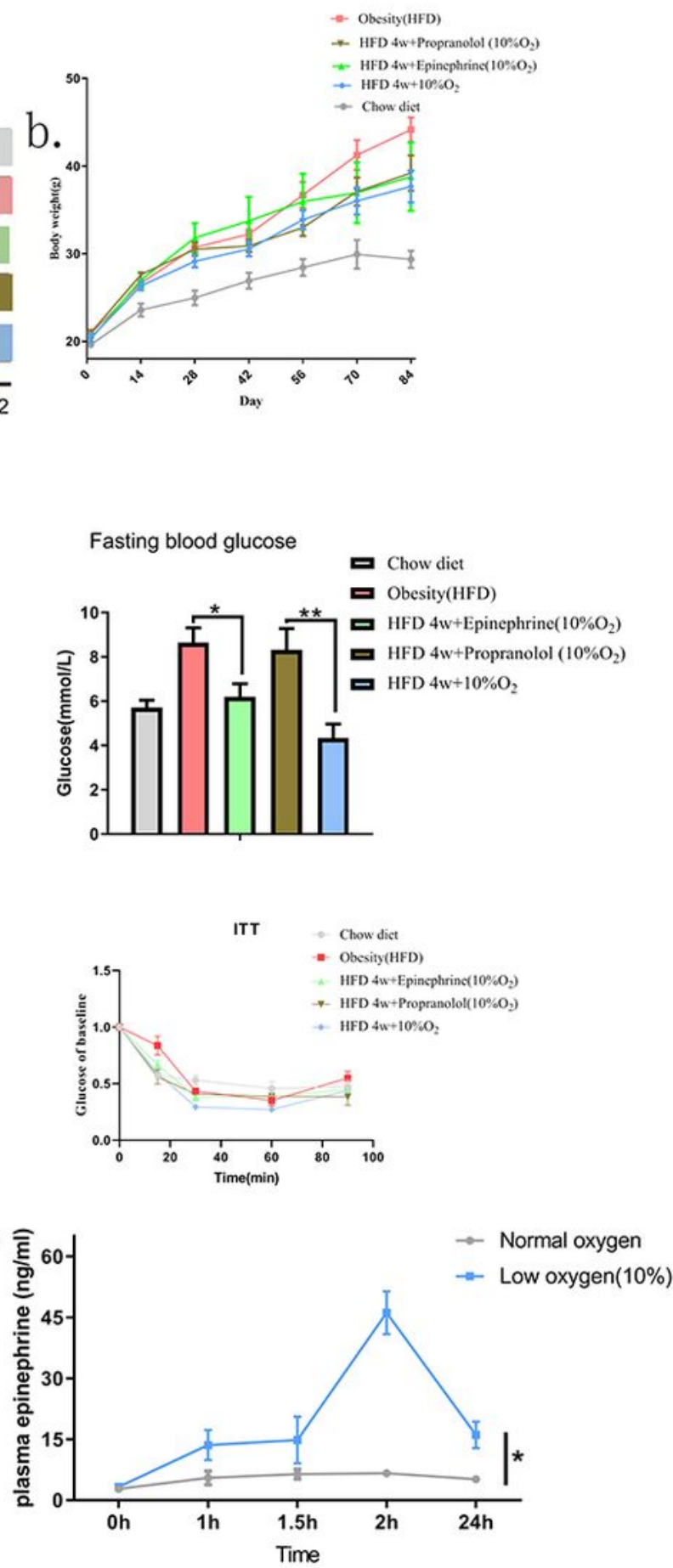

\section{Figure 4}

Blocking the rise of epinephrine will weaken the ability of chronic transient hypoxia environment to reduce the weight of mice and improve glucose tolerance (a) The group of experimental mice $(n=8)$. $(b, c)$. Changes in the weight gain of mice during the experiment. (d,e,f,). Mice's GTT, ITT and fasting blood glucose. $(g, h)$. The changes in the concentration of epinephrine in the serum of mice. 


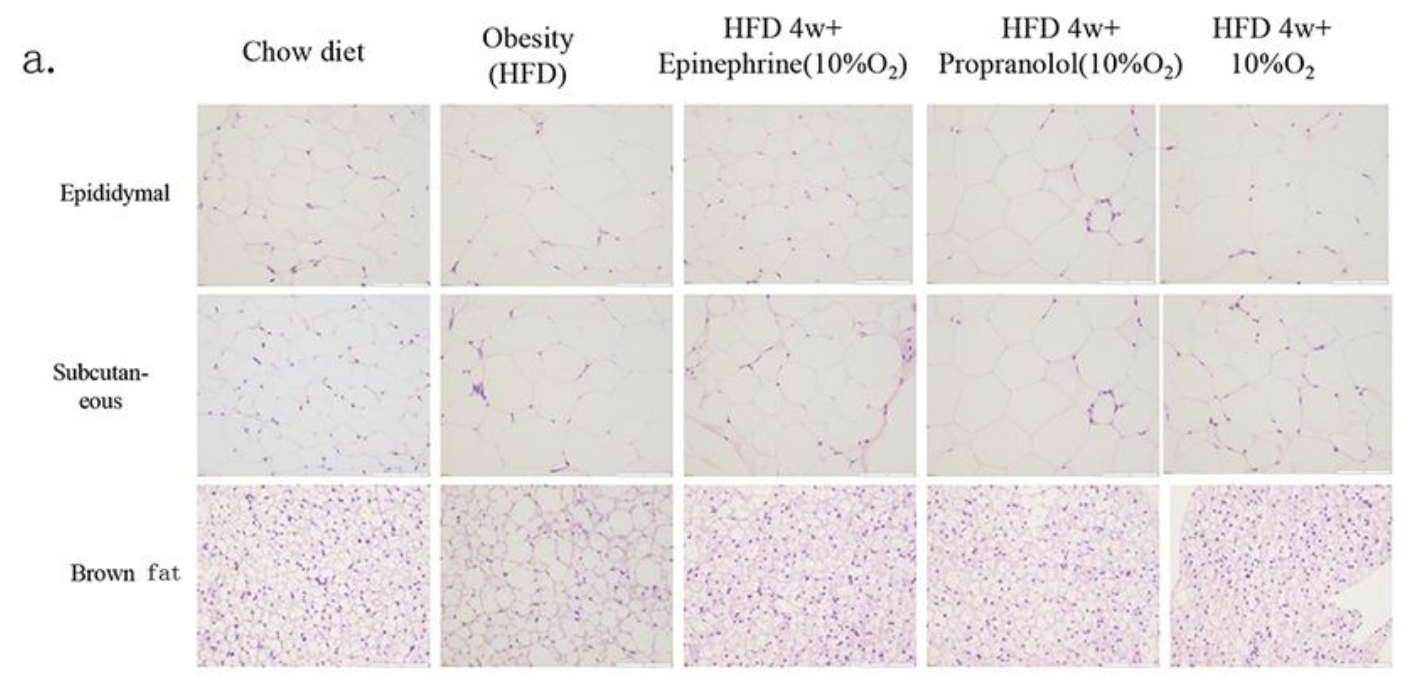

b.

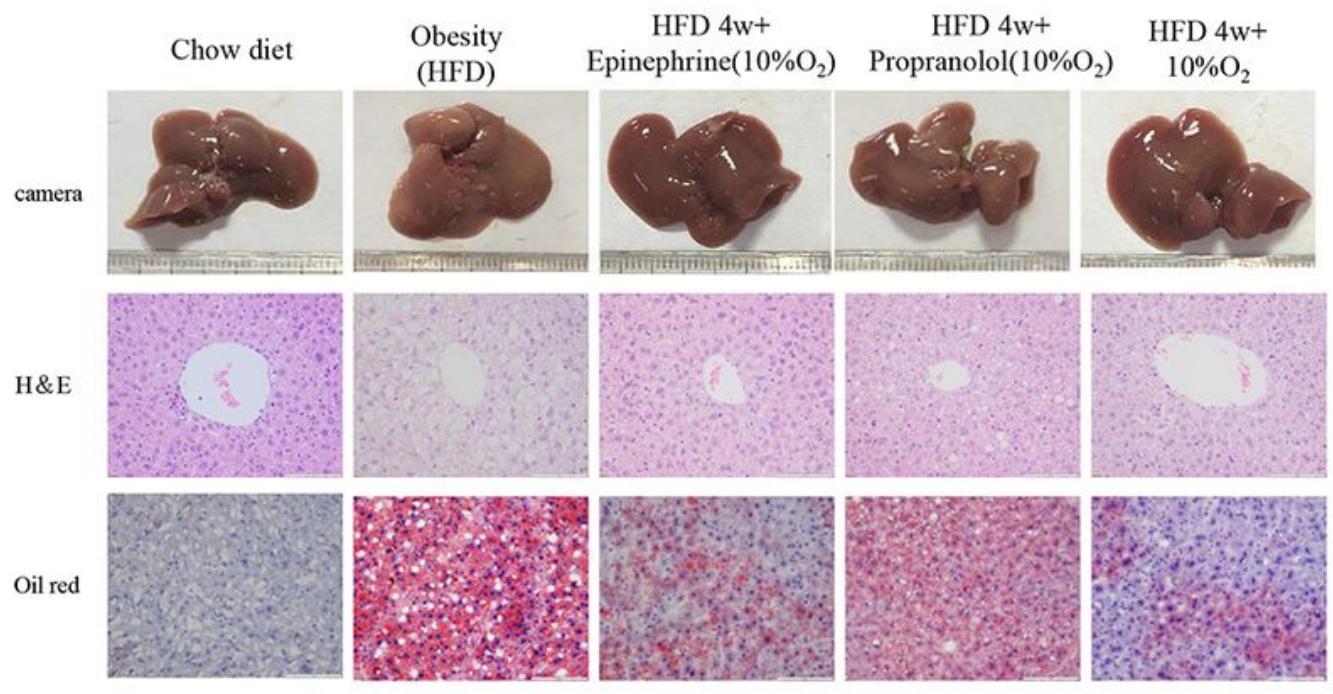

C.

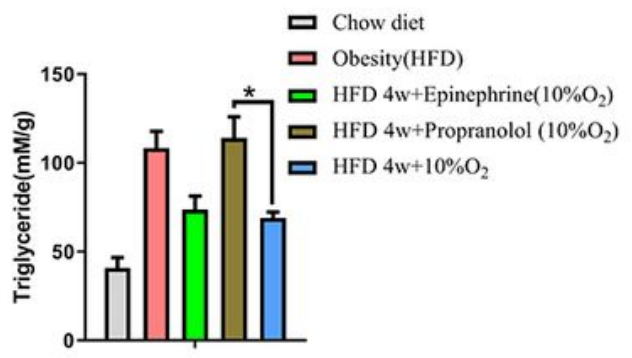

d.

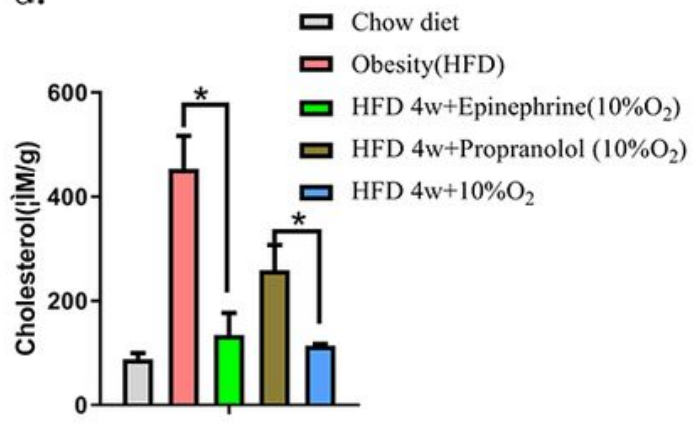

\section{Figure 5}

Blocking the rise of epinephrine will weaken the ability of chronic transient hypoxia environment to reduce the fat content of mice and alleviate fatty liver (a) H\&E staining results of mouse white fat and brown fat. (b). The appearance of mouse liver and H\&E, oil red $\mathrm{O}$ staining results. (c,d). Cholesterol and triglyceride content in mouse liver. 


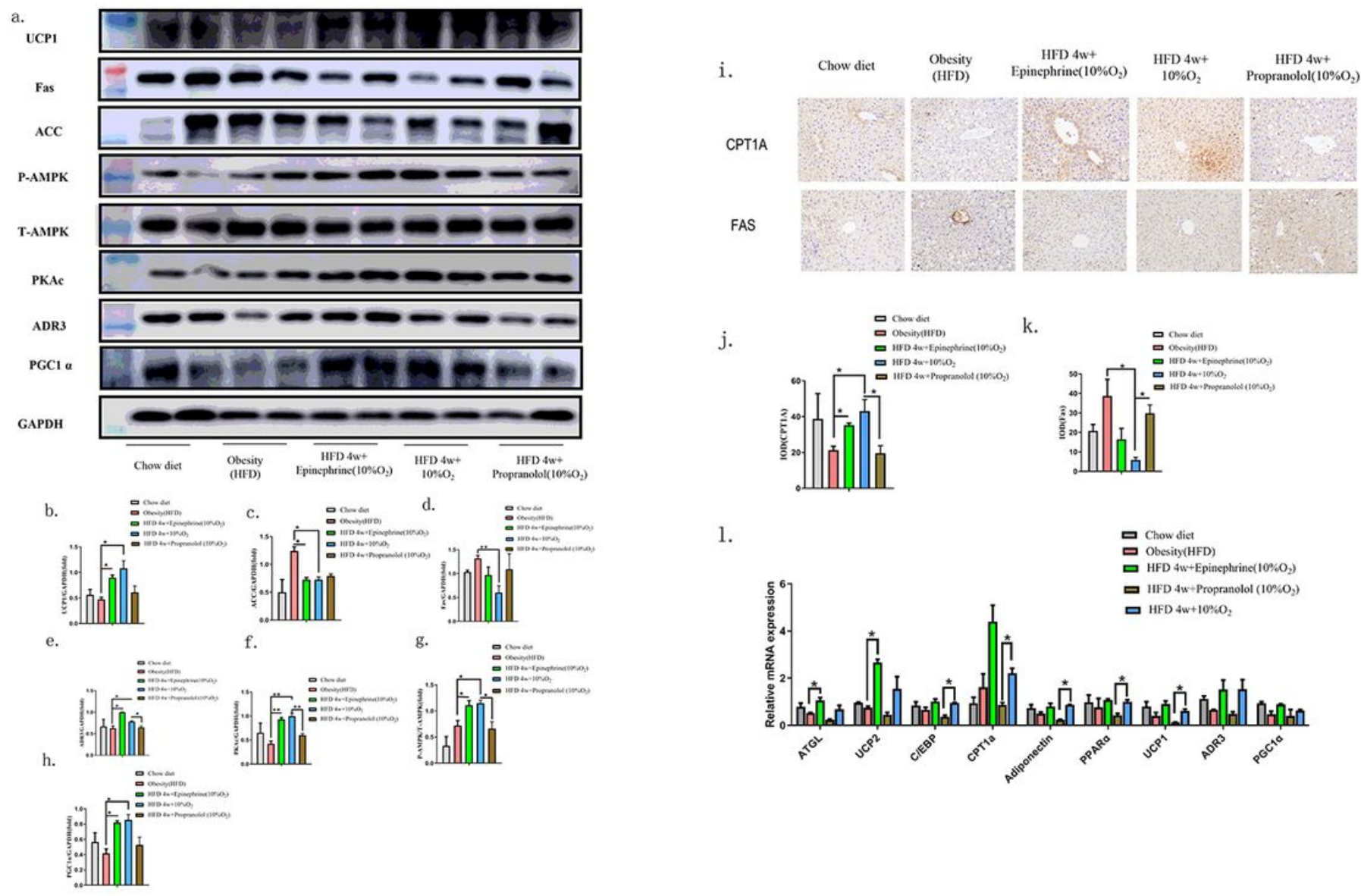

Figure 6

Blocking epinephrine elevation reduces the ability of chronic transient hypoxia environment increment in liver fat oxidation (a,b,c,d,e,f,g,h). Expression of UCP1, ACC, Fas, ADR3, PKAc, P-AMPK and PGC1a proteins in mouse liver by western blot. $(\mathrm{i}, \mathrm{j}, \mathrm{k})$. Expression of CPT1A and Fas proteins in mouse liver by IHC. (I). Lipid synthesis and catabolism related genes expression in mouse liver. 

Chow diet
Obesity
$\begin{array}{cc}\text { HFD 4w+ } & \text { HFD 4w+ } \\ \text { Epinephrine }\left(10 \% \mathrm{O}_{2}\right) & 10 \% \mathrm{O}_{2}\end{array}$
(HFD)
HFD $4 w^{+}$
Propranolol $\left(10 \% \mathrm{O}_{2}\right)$

a.
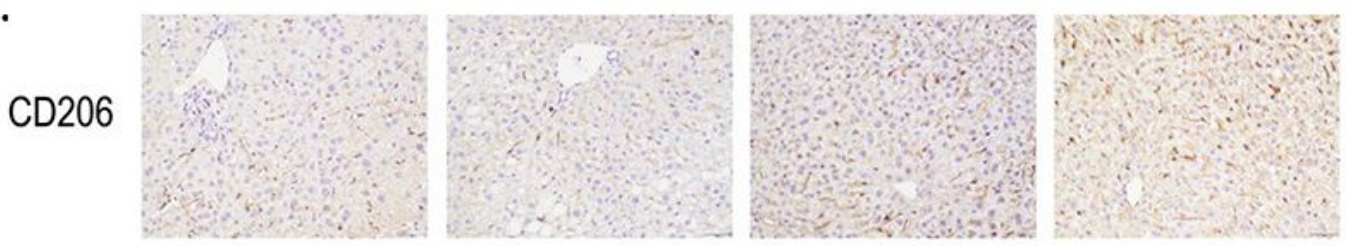

b.

CD206

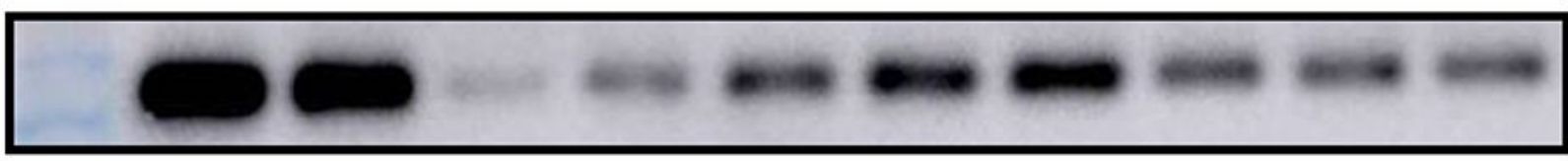

GAPDH

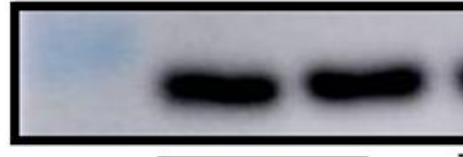

Chow diet
Obesity

(HFD)
HFD 4w+

Epinephrine $\left(10 \% \mathrm{O}_{2}\right)$
HFD 4w+ $10 \% \mathrm{O}_{2}$
HFD 4w+ Propranolol $\left(10 \% \mathrm{O}_{2}\right)$ c.

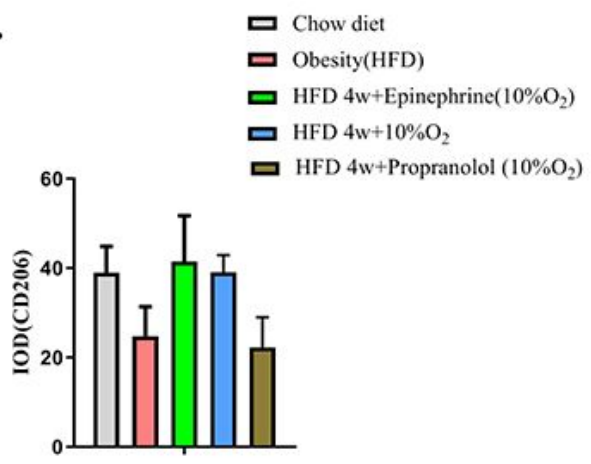

d.

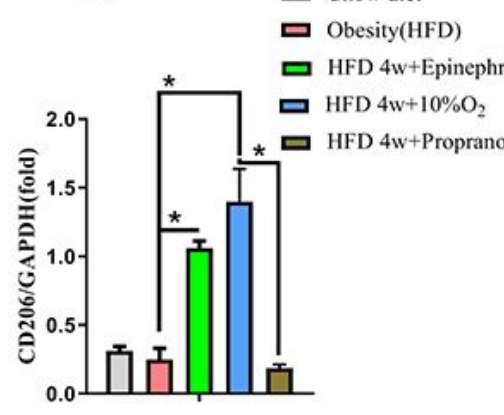

e.

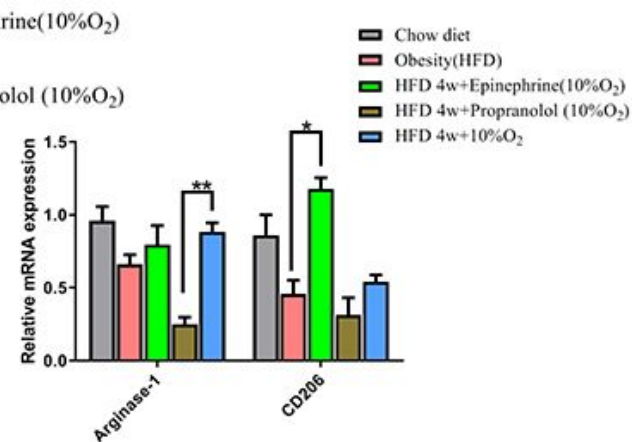

\section{Figure 7}

Blocking epinephrine elevation reduces the ability of chronic transient hypoxia environment to increase the expression of M2 macrophages in the liver $(\mathrm{a}, \mathrm{c})$. Expression of CD206 proteins in mouse liver by IHC. $(b, d)$. Expression of CD206 proteins in mouse liver by western blot. (e). M2-type macrophages marker related genes expression in mouse liver. 


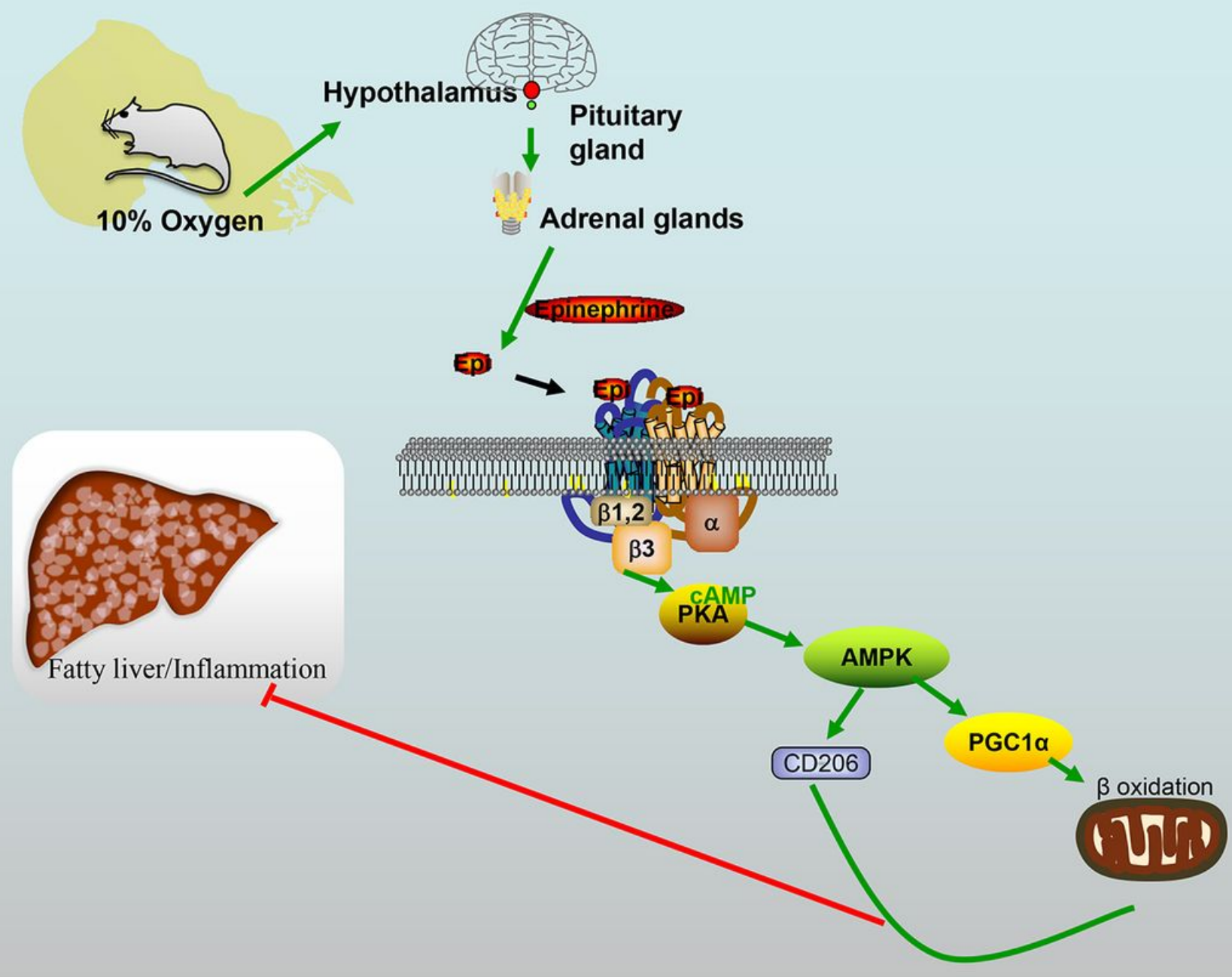

Figure 8

A model for chronic transient hypoxia alleviates high fat diet-induced obesity and fatty liver in C57 mice by upregulating epinephrine levels and activation of AMPK 